\title{
Professor Szczeklik: passion for medicine, science and life
}

\author{
Anetta Undas \\ Institute of Cardiology, Jagiellonian University Medical College, Kraków, Poland
}

Correspondence to:

Prof. Anetta Undas, MD, PhD, Instytut Kardiologii, Uniwersytet Jagielloński, Collegium Medicum, ul. Prądnicka 80 31-202 Kraków, Poland, e-mail:mmundas@cyf-kr.edu.pl Received: March 26, 2012. Accepted: March 26, 2012 Pol Arch Med Wewn. 2012; (Special Issue): $52-54$

Copyright by Medycyna Praktyczna Kraków 2012
I met him in October 1988 as I was a newly elected chief of students' scientific movement at the Medical Academy of Nicolaus Copernicus in Krakow. A friend of mine was actively involved in a students' scientific activity at the 2nd Department of Internal Medicine in Krakow and encouraged me to come there. Professor Szczeklik, the head of this department, and his team had the reputation of being the best place to learn internal medicine in the city. Professor Szczeklik's courage and integrity in the years 1980-1989 as a member of the outlawed Solidarity Trade Union and an active supporter of the Independent Students' Association, was also most important to me. After a few minute conversation, he asked me to join three other students doing experiments on fibrinolysis. To set up an euglobulin lysis assay at my spare time working in small rooms at level -1 at 8 Skawińska Street was my first scientific task. Thus, with some trepidation, I entered the field of research under the guidance of Professor Szczeklik.
He was the right person, one of the best Polish scientists among clinicians and the senior author of original papers in top medical journals, while working with restricted resources in Poland. He proved "he could do it" and I knew that with him, I also can. And those first years were a life-changing experience in my professional life. At those days, encouraged by the highly enthusiastic research environment provided by Professor Szczeklik, I quickly realized that doing science is fun and research is thrilling. A life-long adventure has begun.

I was aware of the fact that a major field of scientific interest of Professor Szczeklik was aspirin-induced asthma. Blood coagulation appeared to be just an additional field of expertise indirectly linked with asthma through aspirin, an old drug of many faces and still being discovered novel intriguing actions. I read the first papers from his group on myocardial infarction and thrombin formation. He wanted to continue research on antithrombotic

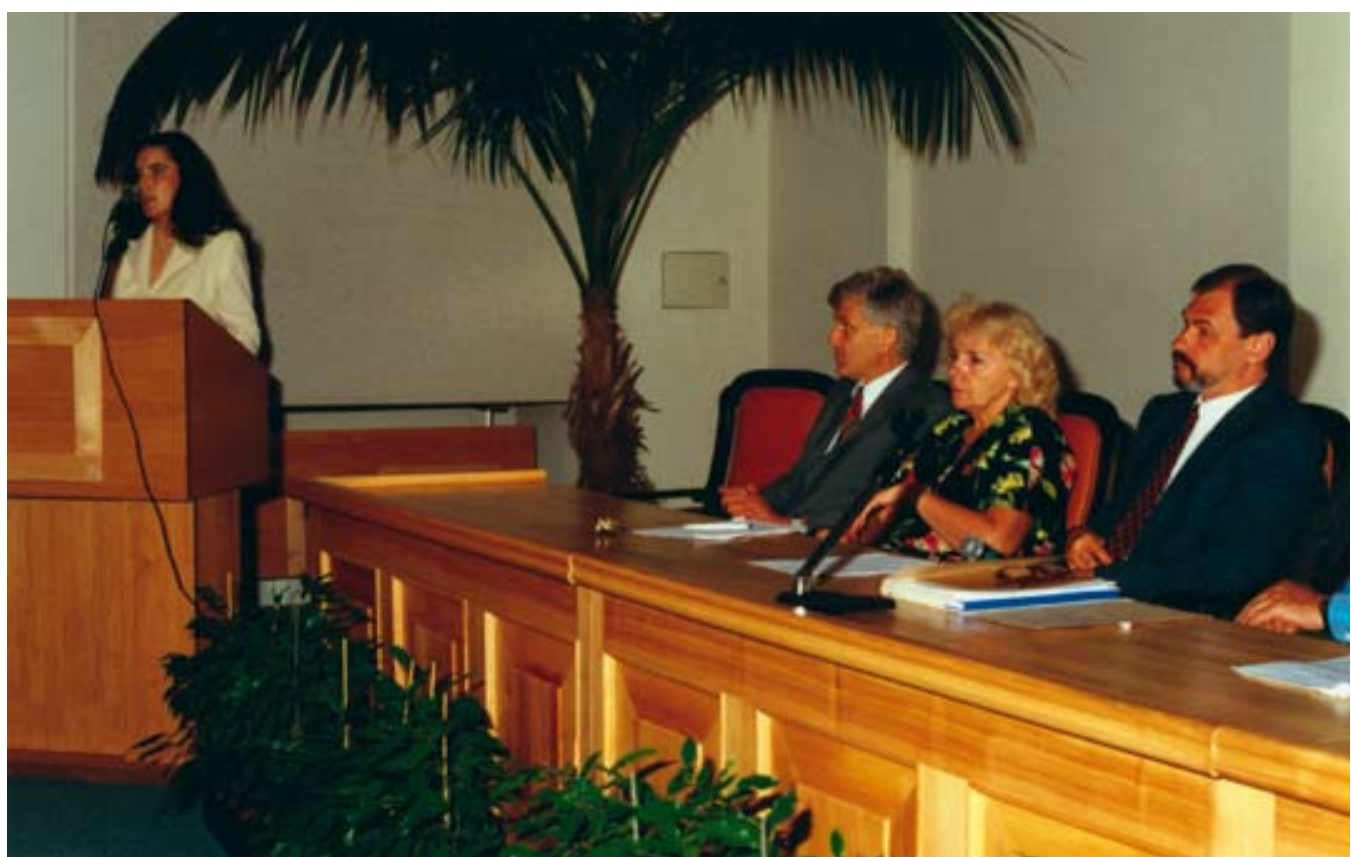

FIGURE 34 Anetta Undas (on the left) at doctoral thesis defence in Krakow on 13 June 1996; at the conference table from the left: Professor Szczeklik, Professor Wiesława Piwowarska, Professor Jacek Musiał 


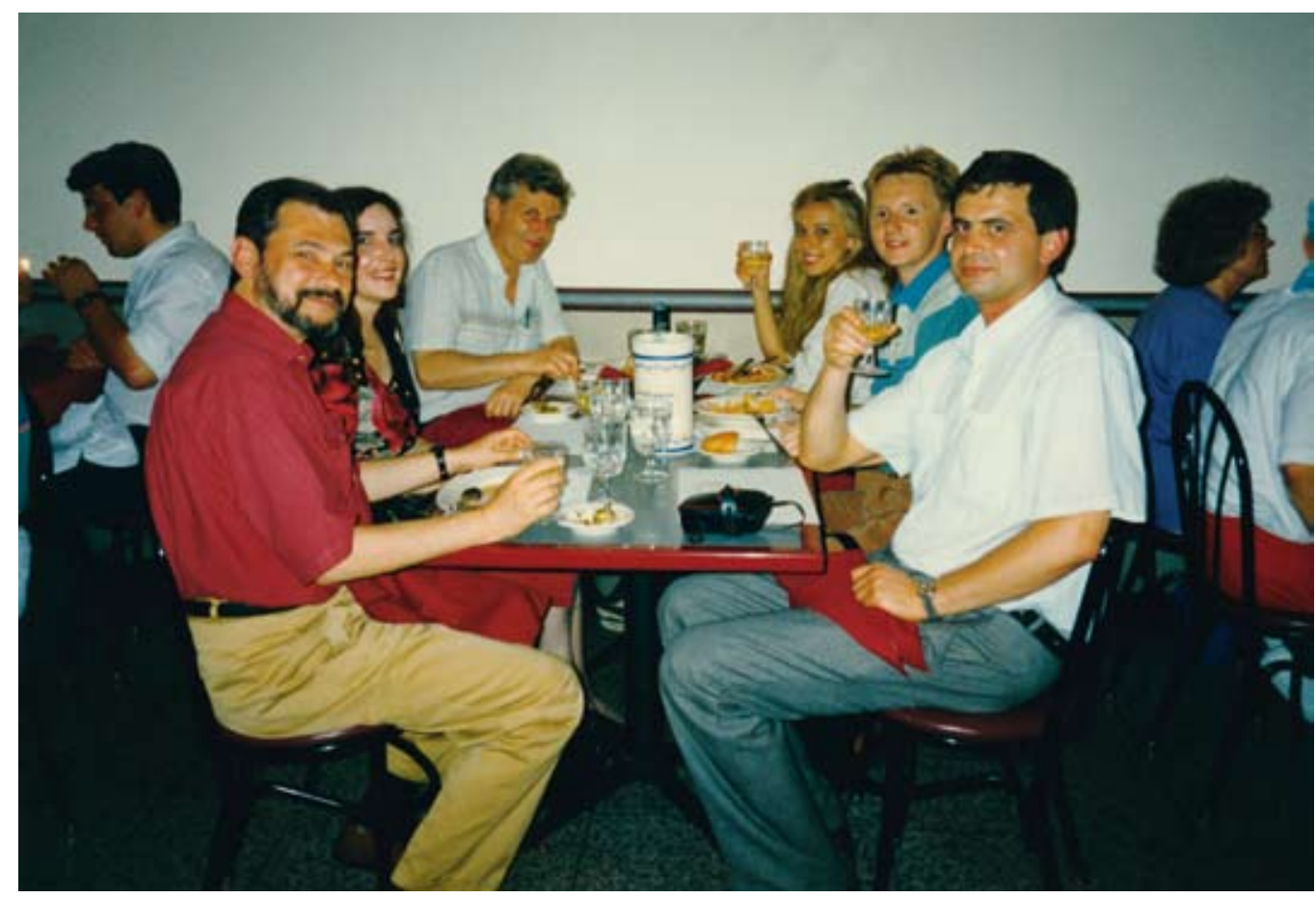

FIGURE 35 Dinner during the Congress of International Society of Thrombosis and Haemostasis, New York, July 1993. From the left: Professor Jacek Musiat, Professor Anetta Undas, Professor Szczeklik, a pharmaceutical company representative, Dr Jakub Swadźba, Dr Jerzy Dropiński

aspirin's modes of action beyond its antiplatelet effects, which has already been supported by a few important contributions starting from mid-1980s. Professor Szczeklik implemented a model of microvascular injury, introduced by Margareta Thorgren in 1983 to measure thromboxane metabolites, to determine kinetics of thrombin generation following standardized skin incisions on a forearm by the use of a bleeding time device. We refined the original method and used it to test other hypotheses cropping up according to the rule that one answer leads to ten new questions.

I did my doctoral dissertation under his guidance in 1996 and its subject was the modulation of aspirin-induced impairment of thrombin generation by plasma cholesterol levels. These studies led to the discovery of beneficial effects of cholesterol-lowering statins on thrombin formation in response to vascular injury. The microvascular injury model was successfully used by Professor Szczeklik's group to assess drug-induced and genetically determined alterations in blood coagulation activated by microvascular injury. Professor Szczeklik was the first or senior author of several papers based on this methodology, including articles that appeared in the most prestigious journals, such as The Lancet, Circulation, Blood, Journal of the American College of Cardiology, and many others. Most of these papers were focused on coronary artery disease and its therapy. By a quirk of fate, this cardiac disease claimed the life of this man who devoted a large part of his life to its exploration.

I think that it is for his enthusiasm and passion for medicine, science, and other facets of life that Professor Szczeklik will be remembered by all who have worked with him. If I were to choose one quality I consider most characteristic of him, it would be passion, which I shared and took delight in. If you know the joy of thrilling anticipation of a new finding, discovering something unexpected you are his soul mate. He was really able to transmit his enthusiasm and passion for science to many of his disciples. His desire to do more, better and something interesting was the driving factor in all his professional endeavors. Professor Szczeklik's extraordinary enthusiasm and passion for science were an inspiration for all people who were fortunate to know and interact with him. His influence, the respect he garnered, and the success he brought doing research in hard times in Poland is the true proof of his achievements as a leader of a scientific team.

He used to wait till the late evening for the results of experiments or the final statistical analysis. This impatience to confirm or refute the working hypothesis in order to make next step on a path that has been started is inherent to scientific passion. He just could not wait to see if we were right or wrong in our concepts. His well-known saying repeated by his coworkers was: "This has not to be done today, it could be ready tomorrow morning." Indeed, if you are waiting for something interesting, important, for the final results or the final version of a manuscript you worked on, timing is vital. And I remember completing a database to 2 a.m. or drafting a manuscript till 4 a.m. (my record time). If we cannot finish our work promptly, we may see a similar investigation on the pubmed.gov published on-line a week later and your findings turn 
out immediately to a report reproducing the original study.

Another facet of his attitude to scientific activity was patience whenever necessary. While preparing a revised version of the manuscript following additional reviewer's comments, while sending the manuscript to the nth journal, while repeating experiments and designing new ones to figure out why the data obtained are inconsistent or odd. And he never required from his coworkers more than from himself, being actively involved at all stages of any project till the battle for a decent paper based on the results.

He have always had one foot in the clinic and the other in the lab. He taught us that clinical observation, every odd result, can be the primary inspiration in research. He knew that for physicians, the combination of clinical and laboratory work is most stimulating. In clinical work, he had a number of brilliant diagnostic and therapeutic ideas. His clinical acumen was second to none. He was good at solving diagnostic riddles in patients with rare disease manifestations or uncommon laboratory abnormalities and at seeing something unusual and important in some ordinary (to the rest of us) cases. Although he strongly supported the implementation of the current best knowledge in internal medicine coming from the evidence-based guidelines and textbooks, he knew that good clinical practice is to learn from real-life "cases" presenting with multiple problems. He taught us that we cannot be good doctors without continued education, information from the latest trials and observations from the most recent issues of top medical journals. He used to make notes in a small booklet during ward rounds. Then on the next day, he came up with some new ideas on the cases helping make accurate diagnoses.

Professor Szczeklik was not generous on praises. Once he told me a story that happened in Great Britain. A couple had a son who did not say a word since his birth. At the age of 10 , the boy suddenly said at dinner: "This soup is not salty". Both parents were amazed and overjoyed. "You can speak". They cried with happiness. "Why have you not spoken to us during the past years?" The boy replied. "Till today, everything has been fine". He believed that everyone should have been working at his or her best. His strategy for paying attention to problems, mistakes, or shortcomings at work appeared at first hard to be accepted. Although I am still persuaded that "well done" spoken out in front of team members by a boss can work wonders, now I see his point, i.e., his belief that a scientist's motivation and dedication ought to lie inside him or her and they should not depend on nice words, awards, appreciation, and acknowledgments. Doing investigations, both experimental and clinical, is tough and often disappointing. He was quite aware of it. I learnt from him how to be perseverant in dealing with negative reviews, to address sometimes harsh comments, and to cope with methodological pitfalls. He persisted through obstacles and recovered from setbacks. He felt that without these features, one cannot be successful in science or in other professional activities.
He disliked watching TV. "A thief of time" he repeated. He admired Greek philosophers and writers, together with Greek mythology. Three years ago while sitting on the train, I saw him reading and taking down notes from Homer's Odyssey. Most of us have forgotten Homer just as school days. I could see in his hands also contemporary literature, for example Never let me go by Kazuo Ishiguro. We talked on the plot of this science fiction novel and he was able to see in it uncertainties of the post-genome era as well the traces of old myths. He also liked English poets, including Thomas Eliot and Seamus Heaney. He liked Dutch painting, in particular Rembrandt. In 1993, during the ISTH Congress in New York we walked for 4 hours to find the Frick collection and look at the Polish Rider. He believed that broad versatile interests are needed to self-develop, to understand more, to see more and to be able to do more in life. Everything around us, particularly art, could be an inspiration in work and life in general. He deeply believed that medicine and art are interrelated and might stimulate each other revealing new paths or novel ideas in all human activities. Few of us could look at in this way.

Professor Szczeklik did a lot to integrate his growing team, clinicians, researchers, and nurses. He liked to talked to people in his spare time, while walking along the corridor, and they knew that he was genuinely curious and concerned about their health problems or others. I think it endearing that for example, among the things that Professor Szczeklik thought important was having dinner with young colleagues at congresses held abroad.

When the Polish Archives of Internal Medicine (Pol Arch Med Wewn) has changed the publisher and the office has been moved to Krakow in 2007, Professor Andrew Szczeklik has become the Head of the National Scientific Board in this journal. He supported us in many ways and cared about the journal to the very end. I spoke to him on the phone for the last time just a week before his death. We chatted about many things, mostly about the future. Staying at the hospital, he still inquired about the impact factor of the journal and its current problems. I could do nothing but ensure again, based on our data from November 2011, that the estimated first impact factor of our journal will be around 1.3. I very much hope that the final value published in June 2012 would be satisfying to him. My last tribute to him.

Like all strong personalities not free of weaknesses, he has been loved or hated, and always respected. Nothing tepid, indifferent, or moderate has been associated with Professor Szczeklik. We all have taken something from him to build on our own qualities, careers and lives by agreeing with him or by opposing him. Tiny pieces of his charismatic personality in all shapes and shades will survive in all of us who have had this oppor tunity to know him and work with him and for him for a sufficiently long period of time. Hard to believe that he passed away... Now everything in my professional life will be different. 